\title{
NÚCLEO DE ASSESSORIA JURÍDICA ALTERNATIVA DA UESB: O DIREITO PARA ALÉM DOS MUROS DA UNIVERSIDADE
}

\author{
Alexandre Garcia Araíjo ${ }^{1}$ \\ Izadora Silva Guedes ${ }^{2}$
}

\section{RESUMO}

O presente trabalho tem como finalidade abordar a construção da Assessoria Jurídica Universitária da UESB, denominada Núcleo de Assessoria Jurídica Alternativa (NAJA); esta experiência se reivindica como extensão popular de caráter emancipatório, e tem se desenvolvido nas salas de aula, auditórios e corredores da universidade, além das ocupações e assentamentos dos Movimentos Sociais Populares. Para tanto, será traçado um panorama geral da conjuntura da Educação Superior e da Educação Jurídica, pois não há como apresentar a proposta da AJUP sem problematizar os referidos temas.

Palavras-chave: Ensino Jurídico. Extensão Popular. Assessoria Jurídica Universitária Popular.

\footnotetext{
${ }^{1}$ Graduando em Direito pela Universidade Estadual do Sudoeste da Bahia (UESB), Membro Fundador do Grupo de Estudos em Direito Crítico da UESB, Membro Fundador do Núcleo de Assessoria Jurídica Alternativa (NAJA-UESB). E-mail: xando_mtb@hotmail.com.

${ }^{2}$ Graduanda em Direito pela UESB, Membro Fundadora do Grupo de Estudos em Direito Crítico da UESB, Membro Fundadora do Núcleo de Assessoria Jurídica Alternativa (NAJAUESB). E-mail: izadorasguedes@gmail.com
}

\begin{tabular}{l|l|l|l|l}
\hline Revista Extensão \& Cidadania & Vitória da Conquista & v. 1, n. 1 & p. 169-184 & jan./jun. 2013 \\
\hline
\end{tabular}




\section{RESUMEN}

El presente trabajo tiene por objeto abordar la construcción del Asesoramiento Legal Universitario de UESB, llamada Núcleo de Servicios Legales Alternativos (NAJA); esta experiencia se reivindica como una extensión popular que visa la emancipación, y ha sido desarrollado en las aulas, auditorios y pasillos de la Universidad, además de las ocupaciones y de los asentamientos de los movimientos sociales populares. Para este fin, será demarcado un panorama general de la situación de la Educación Superior y Educación del Derecho, ya que no hay como presentar la propuesta del AJUP, sin cuestionar estos temas.

Palabras-clave: Educación legal. Extensión Popular. Asesoramiento Legal Universitario.

\section{Introdução}

A “abertura ao outro" é o sentido profundo da democratização da universidade. (SANTOS, 1997, p. 225)

Para os pobres, é dura lex, sed lex. A lei é dura, mas é a lei. Para os ricos, é dura lex, sed latex. A lei é dura, mas estica. (SABINO, 1987, p. 87)

A Assessoria Jurídica Universitária Popular (AJUP) é um instrumento que combina a teoria do Direito Crítico com a Educação Popular. Diferencia-se da relação tradicional entre o saber e o fazer jurídico, pois possui caráter inovador em relação ao método que desenvolve, aos sujeitos que constroem o projeto - e à noção de sujeito - e, também, à finalidade que visa cumprir. Este instrumento surgiu como alternativa à cultura normativo-positivista vigente nos cursos de Direito, eivada de um tecnicismo despolitizado. A vigência desse modelo dogmático implica, segundo Machado (2009, passim), na inadequação entre o saber jurídico e a realidade atual, permeada de conflitos coletivos, de mudanças aceleradas, da emergência de novos direitos, de novos sujeitos, de novas demandas sociais e políticas, etc.

Além disso, o tripé existente nos planos de cursos e que fazem parte da noção de Universidade, raramente se faz presente nos cursos 
de Direito: a pesquisa e a extensão, duas bases que ao somar-se com o ensino compõem a concepção de Educação Superior, são bastante escassas nas Escolas Jurídicas. Com o Curso de Direito da Universidade Estadual do Sudoeste da Bahia (UESB) não é diferente.

Atentos a esta realidade, os membros do Centro Acadêmico Ruy Medeiros (CARM), conjuntamente com outros discentes do curso de Direito ligados ao Movimento Estudantil de Direito, representado pela Federação Nacional de Estudantes de Direito (FENED), encontraram nas AJUP's uma perspectiva do fazer/viver universitário que busca colocar o conhecimento produzido na Universidade a serviço do povo.

Assim, pretende-se abordar, no decorrer desse artigo, sobre a construção da Assessoria Jurídica Universitária da UESB, denominada Núcleo de Assessoria Jurídica Alternativa (NAJA). Essa experiência é reivindicada como extensão popular de caráter emancipatório, e tem se desenvolvido nas salas de aula, auditórios e corredores da universidade, além das ocupações e assentamentos dos Movimentos Sociais Populares. Para tanto, será traçado um panorama geral da conjuntura da Educação Superior e da Educação Jurídica, pois não há como apresentar a proposta da AJUP sem problematizar os referidos temas.

\section{Um breve panorama da educação superior brasileira}

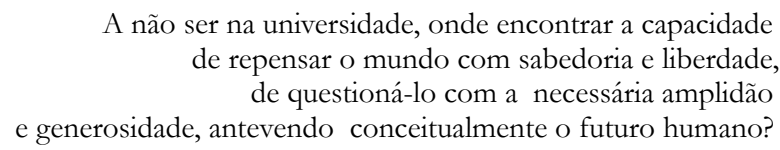

(RIBEIRO, 1991, p. 147)

Com o advento e avanço do projeto neoliberal sobre a educação superior brasileira, os investimentos em Instituições de Ensino Superior (IES) privadas movimentam um mercado milionário entre os empresários brasileiros e estrangeiros. A educação, que é direito da população (art. 205 da Constituição Federal), passa a ser encarada como mercadoria, sendo negociada no Congresso Nacional pelos 
“Tubarões da Educação" 3, e impulsiona a proliferação de faculdades privadas nos rincões de nosso país.

Os maiores financiadores de pesquisas das universidades brasileiras são os grandes conglomerados multinacionais, para quem a qualidade é medida pela produtividade: quanto produz, em quanto tempo produz e qual o custo que produz. Não se questiona a respeito do que é produzido, como se produz e para que ou para quem se produz. Essas entidades ainda acabam utilizando-se da infraestrutura estatal das universidades públicas, e da mão de obra qualificada dos docentes, para criar produtos e tecnologias que não visam atender à população mais carente, mas sim, ao grande capital, assim

[...] os grandes conglomerados multinacionais começam a utilizar a estrutura pública e a mão-de-obra qualificada da Universidade para realizarem pesquisas que serão a base de seus produtos, ou para referendarem informações que lhes trarão benefícios mercadológicos. Sendo assim, o conhecimento produzido serve a determinados interesses e atende a determinadas demandas, quais sejam, as das classes dominantes (ARAUJO, 2011, p. 2).

O governo propagandeia que o acesso ao ensino superior é uma realidade e que a classe trabalhadora é a maior beneficiada por essas ações. Essa informação não é inteiramente uma falácia; todavia, algumas contradições ficam evidentes com a análise de dados oficiais do governo. De acordo com o Censo da Educação Superior, em 2005 as IES privadas respondiam por $73,2 \%$ das matrículas, enquanto o setor público de ensino superior atendia apenas $26,8 \%{ }^{4}$. Ademais, a Pesquisa Nacional por Amostra de Domicílio (PNAD) de 2004, realizada pelo Instituto Brasileiro de Geografia e Estatística (IBGE), apontava que 17,3\% dos jovens frequentavam o ensino superior, sendo que destes, apenas $23,3 \%$ (ou 4,9\% do total) estavam nas universidades públicas (SANTIAGO,

\footnotetext{
${ }^{3} \mathrm{~A}$ bancada da educação é uma das mais fortes do Congresso, sendo composta pelos donos de redes universitárias e de cursinhos preparatórios, e por seus representantes.

${ }^{4}$ Informação retirada de: <http://oglobo.globo.com/educacao/mat/2006/12/12/286999891. asp>. Acesso em: 22 set. 2011.
} 
2008, p. 25). Dessa forma, a classe trabalhadora tem tido acesso ao ensino superior, entretanto, programas como o Programa Universidade para Todos (PROUNI) e o Fundo de Financiamento Estudantil (FIES) são necessários para garantir a permanência desse público naquele espaço - o primeiro programa sustenta as instituições e as isenta de impostos ${ }^{5}$, enquanto o segundo endivida previamente o trabalhador em formação.

\section{Educação jurídica}

Direito é desenganadamente política, e a questão não é ser político ounão o ser, pois não o ser é um disfarce que adota a opção política de natureza conservadora - isto é, não quer que o estudante ou professor "façam política", porque esperam que eles se acomodem docilmente à política oficial, que já tragou a função e a maneira de exercê-la: o Estado é o autor da peça; o dirigente da Faculdade é o produtor e diretor do espetáculo; e a nós cumpriria apenas desempenhar o papel que nos foi distribuído, sem contestar (LYRA FILHO, 1984, p. 30).

\section{É nos marcos de uma Educação Superior orientada por um} projeto neoliberal, conforme mencionado acima, que se encontra também o ensino do Direito. Segundo Machado (2009, p. 74):

[...] os problemas que atualmente afligem a universidade no Brasil, e particularmente o ensino jurídico no país, têm que ser entendidos num contexto maior de crise que atinge estruturalmente tanto a sociedade em geral quanto o próprio Estado brasileiro, desde a organização daquela até a racionalidade e legitimidade deste último [...]. A crise da universidade brasileira enquanto instituição, com repercussão direta no ensino jurídico, tem suas raízes não apenas em problemas internos e organizacionais, mas, sobretudo, em fatores de fundo político, econômico e social que de resto

\footnotetext{
5 "A escola privada hoje no Brasil não é somente um fenômeno educacional, é um fenômeno econômico. $\mathrm{O}$ faturamento do ensino privado já tem peso significativo no PIB; foi estimado pelo IBGE, para o ano de 2004, acima de $\mathrm{R} \$ 50$ bilhões. Talvez nos surpreenda, mas uma das atividades menos regulamentadas pela Receita ou, se quiserem, uma das atividades em que há mais lavagem de dinheiro, é a educação. De tal maneira é a sonegação, que o principal projeto educacional do governo Lula foi a isenção fiscal do ensino superior em troca de bolsas: o PROUNI, que renegociou dívidas em troca de matrículas" (ARCARY, 2008, p. 19).
} 
marcam toda a vida da sociedade brasileira. Trata-se, portanto de uma crise estrutural, cujos efeitos se projetam no tempo, como se ela fosse uma crise permanente.

A crise do ensino jurídico a que se refere Antônio Alberto Machado possui múltiplos fatores, dentre eles podemos assinalar o esgotamento dos paradigmas científicos da ciência do direito como um aspecto fundamental dessa crise, ou seja, além de questões como a proliferação desmesurada dos cursos de Direito ${ }^{6}$ (expansão que obedece puramente a critérios mercadológicos), o modelo pedagógico que é levado a efeito nas faculdades de Direito se mostra como um aspecto determinante dessa crise. Esse modelo pedagógico tem " $\mathrm{O}$ normativismo como único objeto da ciência jurídica, o raciocínio lógico-formal como sua única metodologia, o liberalismo como paradigma ideológico exclusivo e a mentalidade positivista como base do saber jurídico" (MACHADO, 2009, p. 121).

O ensino tecnicista atual privilegia, como principal (e muitas vezes único) modo de ensino, a aula magistral expositiva com base na legislação. As disciplinas são organizadas fundando-se nos códigos e nos comentários destes, tanto em relação ao conteúdo quanto ao método, recorrendo-se a exemplos práticos que mais se esforçam para adequar a realidade à teoria do que extrair da própria realidade o conhecimento. Pressupõe-se que o bacharel em Direito conseguirá entender a norma e em muitos casos aplicá-la, mas não conseguirá contextualizá-la, pois nunca estudou sua finalidade, o contexto em que foi criada, e os resultados que produziu e produz. Dessa última afirmação pode-se deduzir, outrossim, que na realidade o estudante, futuramente bacharel em Direito, não compreende a norma, mas a assimila, absorve.

No entanto, é indispensável perceber que, não obstante o ensino tecnicista/normativista do Direito, a norma não é uma realidade própria isolada da realidade econômica, social e política.

${ }^{6}$ Uma pesquisa do Conselho Nacional de Justiça (CNJ) apontou em 2010, que o Brasil possui mais cursos de direito do que a soma de todo o resto do mundo junto. São cerca de 1.240 no Brasil, contra cerca de 1.100 no restante do planeta. Informação disponível em: < http:/ /www.aldeiagaulesa. net/2011/09/brasil-tem-1240-cursos-de-direito-resto.html>. Acesso em: 14 ago. 2011. 
Assim, quando o estudante internaliza certa norma (já que dificilmente desenvolve um conteúdo crítico), ele internaliza também uma ideologia em função da qual são produzidas as regras jurídicas. O ensino dessa relação de mecanização entre a lei e sua aplicação como se fosse um processo natural prescinde da compreensão da sociedade, da história e da política. Provavelmente tal alienação seja mesmo imprescindível. É dessa forma que o "operador do direito" lida constantemente com o povo, com os direitos difusos e com as diferentes necessidades e demandas sociais, sem conhecer a sociedade e sem conhecer o direito (pode conhecer a norma, mas não o direito).

É impressionante notar como o ensino jurídico hoje consegue ser mais retrógrado e conservador do que entre o fim do século XIX e início do século XX. Nessa época, comentava-se em tom de gracejo que na Faculdade do Largo de São Francisco também se estudava Direito. Isso porque o ensino do Direito ocorria em meio ao estudo da história, da política, da filosofia e da literatura. Não é à toa que personalidades como Rui Barbosa, dentre outras importantes figuras do cenário político, passaram por lá, além de poetas como Álvares de Azevedo. Este cenário propiciava um caráter humanístico, crítico e interdisciplinar ao estudo do Direito. A ausência desse caráter omite na técnica, pretensamente neutra, a manutenção do tipo de sociedade em que vivemos.

Enfim, as palavras do professor da Faculdade de Direito da USP, Alysson Leandro Mascaro, situam bem o lugar do ensino jurídico na reprodução do Direito e da sociedade:

O atual modelo de ensino jurídico brasileiro corresponde plenamente a uma instância necessária da estrutura de reprodução do Direito e da sociedade. Da garantia dos direitos subjetivos à defesa da propriedade privada, a maioria das relações jurídicas que perpassam a sociedade é ensinada ao operador nas faculdades. Daí que a sua formação não está em crise com a reprodução do capitalismo contemporâneo: o Direito que se ensina e o que é concretizado pelo jurista é exatamente aquele necessário à vida do capital [...]. Mudar o ensino jurídico representa mudar o eixo de gravidade do saber 
sobre o Direito, o poder e o justo. Trata-se de uma mudança dialética da própria sociedade e do fenômeno jurídico (MASCARO, 2011, p. 15).

\section{Da extensão universitária que temos à extensão universitária que queremos}

Ou os estudantes se identificam com o destino do seu povo, com ele sofrendo a mesma luta, ou se dissociam do seu povo, e nesse caso, serão aliados daqueles que exploram o povo (FERNANDES, 2010, p. 73).

Ao tratar da extensão universitária, é importante superar o mito da neutralidade positivista e aprofundar as análises sobre o posicionamento político desses projetos de extensão. Em geral, é possível classificar esses projetos, tendo como referencial sua prática pedagógica e marco teórico, em: assistencialistas e emancipatórios. Com base no mesmo referencial, as práticas jurídicas (universitárias ou não), podem ser caracterizadas em: serviços legais tradicionais $\mathrm{x}$ serviços legais inovadores e em assistência jurídica $\mathrm{x}$ assessoria jurídica. ${ }^{7}$

Luz (2008) aponta que a prática assistencialista prioriza os interesses individuais dos assistidos por meio de uma orientação paternalista dos extensionistas, com um caráter quase filantrópico - o indivíduo é encarado como um ser isolado, dissociado das contradições sociais e históricas do mundo em que vive. Além disso, não existe uma comunicação entre os saberes dos extensionistas e dos assistidos, mas sim, uma transmissão da teoria acadêmica para aquela realidade concreta, que possui particularidades e não segue a uma lógica ideal. É o que Paulo Freire concebe como educação bancária:

Trata-se de uma pedagogia do controle, da ausência do diálogo, da ausência da comunicação, do exercício da opressão. Esta se

\footnotetext{
${ }^{7}$ Apesar da palavra "Assessoria", em sentido comum, ser quase sinônima da palavra "Assistência", foi ela escolhida para simbolizar uma metodologia inovadora de extensão. A escolha busca exprimir um significado político contrário às propostas de índole "assistencialista". A postura política da Assessoria, por surgir no espaço discursivo dos movimentos populares, é uma postura de contestação e não de caridade. Busca a Assessoria desconstruir o método assistencialista, contestar a sociedade da exploração do trabalho e rechaçar a Assistência como solução de problemas sociais (FURMANN, 2003, p. 60).
} 
faz presente a partir do discurso e da ação de um dos sujeitos - o (a) educador (a) - e enquanto tal torna-se verbalização, monólogo vazio de sentido e recheado de desrespeito ao outro que é tratado como objeto vazio a ser preenchido por conteúdos escolhidos pelo educador (a) (FREIRE apud SCHNORR, 2010, p. 86).

Já os projetos emancipatórios não buscam encontrar as soluções para o povo, mas sim, com o povo: "a educação é comunicação, é diálogo, na medida em que não é a transferência de saber, mas um encontro de sujeitos interlocutores que buscam a significação dos significados" (FREIRE, 1983, p. 46). O estudante confere ao seu conhecimento uma função social colocando-se como participante de lutas estruturais que beneficiarão toda a sociedade.

A assessoria jurídica trata-se de uma prática insurgente, voltada à realização de ações de acesso à justiça, e também a ações embasadas nas concepções de educação popular, buscando a conscientização dos envolvidos no processo e sua emancipação social; é a busca coletiva de soluções, que vai para além dos marcos institucionais. Celso Fernandes Campilongo, ao formular sobre os serviços legais inovadores e tradicionais, elencou algumas características básicas que os diferenciam e apontam suas perspectivas de atuação.

\section{Quadro 1}

\begin{tabular}{|l|l|l|}
\hline Variáveis & Serviços tradicionais & Serviços inovadores \\
\hline Interesse tutelado & Demandas individuais & Demandas Coletivas \\
\hline Vínculo ético & Individual liberal, microética & Coletivo macroética \\
\hline Serviço & Assistencialista / paternalista & $\begin{array}{l}\text { Conscientizador e } \\
\text { organizador }\end{array}$ \\
\hline $\begin{array}{l}\text { Padrão econômico da } \\
\text { clientela }\end{array}$ & Definição de pobreza & Definição da tutela \\
\hline Relação cliente/advogado & Vertical & Horizontal \\
\hline Conhecimento & Sacralizado & Desmistificado \\
\hline Perfil profissional & Técnico jurídico & Multiprofissionalismo \\
\hline Acesso à justiça & Restrito ao Poder judiciário & $\begin{array}{l}\text { Para além do Poder } \\
\text { Judiciário }\end{array}$ \\
\hline
\end{tabular}

Fonte: Campilongo (apud LUZ, 2008, p. 65). 


\section{Das assessorias jurídicas populares e sua organização}

Quando uso uma palavra - disse Humpty Dumpty em tom escarninho - ela significa exatamente aquilo que eu quero que signifique... nem mais nem menos.

- A questão - ponderou Alice - é saber se o senhor pode fazer as palavras dizerem coisas diferentes.

- A questão - replicou Humpty Dumpty - é saber quem é que manda. É só isso.

(CARROL, 1977, p. 196).

Uma das experiências de serviço legal inovador é a Assessoria Universitária; prática realizada por estudantes de direito, em ambiente de universidades, com uma organização autônoma em relação à administração destas. Essa experiência de projetos de extensão, que tem como característica fundamental o protagonismo e a autogestão estudantil, tem ocorrido no âmbito nacional e sul-americano. Os primeiros grupos a desenvolver estes serviços foram os Serviços de Apoio Jurídico (SAJU's) da Universidade Federal da Bahia (UFBA) e da Universidade Federal do Rio Grande do Sul (UFRGS). Luz (2008, p. 124-154) aponta algumas características comuns entre estes grupos:

a) Diferenciação entre os conceitos e as práticas de assistência jurídica, entendida como apoio jurídico individual, e de assessoria jurídica, entendida como apoio jurídico coletivo;

b) Autonomia decisória em relação à administração das universidades, sendo formadas e geridas por iniciativa exclusiva dos estudantes;

c) Desenvolvimento de projetos de extensão e/ou pesquisa, em atividades permanentes ou sazonais;

d) Ampliação das práticas jurídicas para além do âmbito forense;

e) Interação institucional com a universidade a partir da ocupação de seus espaços públicos, ao tempo que promovem atividades de caráter social.

$\mathrm{Na}$ década de 90 foi fundada a Rede Nacional de Assessorias Jurídicas Universitárias (RENAJU), a fim de congregar os grupos 
que já desenvolviam AJUP's, bem como divulgar e multiplicar suas práticas. Além disso, a rede organiza encontros que servem de aproximação entre estudantes que se interessam pela Assessoria Jurídica, para a capacitação política e a troca de experiências. Hoje, a RENAJU conta com 23 núcleos de todas as regiões do Brasil e a maior parte se concentra no Nordeste e no Sul (PEREIRA; OLIVEIRA, 2009, p. 165).

A Rede busca também, baseando-se nas discussões ligadas às atividades de Assessoria Jurídica, definir princípios e métodos de atuação. Um entendimento predominante na Rede é o de que a Assessoria não precisa envolver necessariamente a atuação judicial. Por fim, cabe trazer algumas anotações de Furmann (2003) sobre a delimitação principiológica apresentada na oficina de capacitação do Serviço de Assessoria Jurídica Universitária Popular (SAJUP-UFPR):

1. Superação do individualismo e preferência pelo coletivo (negar o individualismo);

2. Participação Comunitária e Acadêmica Horizontais para Conscientização (negar o paternalismo e a subordinação);

3. Construção de um Direito Crítico (negar o dogmatismo e o positivismo jurídicos);

4. Presentificação (negar o absenteísmo).

\section{"E o que foi feito é preciso conhecer": surgimento, metodologia e intervenções do NAJA na comunidade}

A cabeça pensa onde os pés pisam.

O caminho se faz caminhando.

(Ditado popular)

Foi justamente em um período de mobilização universitária que as atividades do NAJA se iniciaram. Em abril de 2011, durante a greve estudantil e docente, aproximadamente 15 estudantes de Direito começaram a se reunir para discutir e compreender a proposta das Assessorias Jurídicas Universitárias, sua importância no contexto da UESB e que metodologia poderia ser utilizada para sua implementação a curto e médio prazo. 
A priori, o entendimento era o de que não seria possível começar a intervir na realidade sem um maior aparato teórico, haja vista que esse modelo de extensão rechaça os vícios do senso comum acadêmico e da educação bancária. Destarte, iniciou-se um grupo de estudos a posteriori, batizado como Grupo de Estudos em Direito Crítico da UESB - para dar conta de três eixos centrais: Educação, Carreiras Jurídicas e Direito Crítico, e Extensão Emancipatória e Educação Popular. Primando pelo protagonismo estudantil, o método ocorreu (e ocorre) da seguinte maneira: 1) coletivamente, escolhem-se as temáticas a serem abordadas; 2) um texto é indicado para a leitura coletiva e discussão na reunião subsequente; 3) dois integrantes se habilitam para facilitar esse texto com uma exposição sucinta de suas ideias centrais, trazendo ao grupo elementos que propiciem o debate; 4) outro membro do grupo faz a relatoria das discussões, posteriormente transformando-a em uma síntese, que é compartilhada com o grupo e arquivada para os futuros integrantes; 5) ao final, outras pessoas se dispõem a explanar o texto da semana seguinte, dando sequência ao ciclo de estudos. ${ }^{8}$

O passo seguinte foi compreender melhor como funciona a sociedade, e as peculiaridades da realidade brasileira, ao debater questões de Gênero, Reforma Agrária, Direito e Marxismo e Direito à Moradia e ao Espaço Urbano. O método sofreu uma pequena alteração em algumas reuniões, ou seja, contou com a participação de alguns docentes e militantes de movimentos sociais para facilitarem os textos. Vale ressaltar, que o Grupo de Direito Crítico foi muito importante para agregar as pessoas que não conseguiram participar desde o início, além de despertar a inquietação e criticidade nos integrantes do projeto, provocando uma agitação no Curso.

Após muitos momentos de leitura e debate, foi marcada uma atividade de vivência e capacitação, a fim de subsidiar os integrantes do Grupo de Direito Crítico para que estabelecessem um planejamento das intervenções práticas a serem efetivadas. Essa atividade foi realizada no Assentamento Zumbi dos Palmares, do Movimento

\footnotetext{
${ }^{8}$ Os verbos foram utilizados no presente, pois as atividades do Grupo de Estudos em Direito Crítico continuam ocorrendo da mesma maneira como iniciaram.
} 
dos Trabalhadores Desempregados (MTD), e foi acompanhada por integrantes do Núcleo de Educação Popular do SAJU da UFBA, que foram convidados para compartilhar experiências e contribuir no processo de formulação. Após as discussões fora decidido que as reuniões do Grupo de Direito Crítico seriam mantidas quinzenalmente (antes semanais), no intuito de trazer novos membros para o NAJA, dar seguimento à sua capacitação permanente e levar os debates e provocações realizados no interior do núcleo para o restante da Universidade. No que toca às atividades práticas, o verbo almejado foi experimentar. Como um contato com o MTD já havia sido feito, e a sua demanda era/é latente, foi iniciado um trabalho com o movimento, mas com possibilidades e vontade de conhecer e trabalhar com outros sujeitos sociais (como os remanescentes quilombolas, periferias da cidade, e outros movimentos sociais populares).

Atualmente, o trabalho do NAJA com o MTD está tomando corpo. Houve uma ocupação de uma área rural improdutiva e o núcleo acompanhou todo o processo, tanto na parte jurídica, para evitar qualquer violação de direitos, como na parte laboral, ajudando a levantar os barracos e organizar o novo acampamento. Oficinas de Educação em Direitos Humanos estão sendo realizadas com os moradores do Assentamento Zumbi dos Palmares, do Acampamento Santo Dias, e do novo acampamento, além de um trabalho específico com a juventude. Ademais, o contato contínuo é uma das premissas do NAJA, já que a relação de confiança e companheirismo do movimento e seus integrantes para com o núcleo - e vice-versa - só pode ser construída por meio da pedagogia do exemplo e do sentimento de pertença da classe trabalhadora.

\section{Considerações Finais}

A implementação do Núcleo de Assessoria Jurídica Alternativa inaugurou um novo período na história do Curso de Direito da UESB. Rompeu com a apatia característica dos atores sociais que

\footnotetext{
${ }^{9}$ Serviço de Apoio Jurídico da Universidade Federal da Bahia.
} 
vivenciam o Curso, rompeu com a mesmice do dogmatismo ensinado nas salas de aula, rompeu até com as mudanças comuns, aquelas que chegam a contestar o modelo de ensino que é levado a efeito nos cursos e cuja criticidade não consegue ir além de palestras e debates que não extrapolam o espaço dos auditórios. O NAJA, reunindo os ensinamentos de Paulo Freire e Lyra Filho, visa a intervenção social do saber jurídico, valorizando a participação popular e percebendo o espaço universitário como palco privilegiado para a produção de embates ideológicos contra-hegemônicos por outra educação jurídica (OLIVEIRA, 2011).

A vocação da Assessoria Jurídica Popular Universitária é a luta do povo, seu modo de atuação é lutar com o povo. Dito isto, relembramos com entusiasmo as poéticas palavras de Noel Delamare (1984), pseudônimo de Roberto Lyra Filho, um dos maiores juristas críticos brasileiros:

Não me lamento porque canto

Faço do canto manifesto

Sequei as águas do meu pranto

Nos bronzes fortes do protesto

Acuso a puta sociedade

Com seus patrões, seus preconceitos

O teto, o pão, a liberdade

Não são favores, são direitos. 


\section{Referências}

ARAÚJO, Alexandre Garcia. Universidade e transformação social. Disponível em: <http://ened2011.files.wordpress.com/2011/07/ trabalho-alexandre-garcia.doc >. Acesso em: 14 ago. 2011.

ARCARY, Valério. Observações da crise da Educação Pública. In: ESTUDO, trabalho e luta: a caminho da educação popular. Piracicaba-SP: FEAB/ABEEF, 2008. Disponível em: <http://abeef.files.wordpress. com/2010/04/cartilha-de-educacao-popular1.pdf $>$. Acesso em: 21 maio 2011.

CARROL, Lewis. As aventuras de Alice através do espelho. Rio de Janeiro: Fontana/Summus, 1977.

DELAMARY, Noel. Da cama ao comício, poemas bissextos. Brasília: Edições Nair, 1984.

FERNANDES, Florestan. Vida e obra. São Paulo: Expressão Popular, 2010.

FREIRE, Paulo. Extensão on comunicação? 7. ed. Rio de Janeiro: Paz e Terra, 1983.

FURMANN, Ivan. Assessoria jurídica universitária popular: da utopia estudantil à ação política. 2003. Monografia (Trabalho de Conclusão de Curso) - Universidade Federal do Paraná (UFPR), Curitiba, 2003.

LUZ, Vladimir de Carvalho. Assessoria jurídica popular no Brasil: paradigmas, formação histórica e perspectivas. Rio de Janeiro: Lúmen Júris, 2008.

LYRA FILHO, Roberto. Por que estudar direito, hoje? Brasília: Nair, 1984.

MACHADO, Antônio Alberto. Ensino jurídico e mudança social. 2. ed. São Paulo: Expressão Popular, 2009.

MASCARO, Alysson Leandro. Horizontes do ensino jurídico na atualidade. Revista MPD Dialógico, São Paulo: MPD, ano 7, n. 34, p. 2829, jul. 2011. Disponível em: < http://www.mpd.org.br/img/userfiles/ file/Dialogico34_4versao\%5B1\%5D.pdf>. Acesso em: 15 set. de 2011. 
OLIVEIRA, Assis da Costa. AJUP: movimento estudantil ou serviço legal? Disponível em: <http://assessoriajuridicapopular. blogspot.com/search/label/Assessoria $\% 20 J u r \% C 3 \% A D d i c a \% 20$ Universit\%C3\%A1 ria\%20Popular>. Acesso em: 23 set. 2011.

PEREIRA, Sumaya Saady Mohry; OLIVEIRA, Assis da Costa. Rede Nacional das Assessorias Jurídicas universitárias: história, teoria e desafios. Revista da Faculdade de Direito da UFG, Goiânia: KELPS, v. 33, n. 1, p. 152-166, jan./jun. 2009.

RIBEIRO, Darcy. A universidade necessária. 5. ed. São Paulo: Paz e Terra, 1991.

SABINO, Fernando. A falta que ela me faz - crônicas. Rio de Janeiro: Record, 1987.

SANTIAGO, Oberdan Rafael P. L. Universidade(s). In: ESTUDO, trabalho e luta: a caminho da educação popular. Piracicaba-SP: FEAB/ABEEF, 2008. Disponível em: < http://abeef.files.wordpress. com/2010/04/cartilha-de-educacao-popular1.pdf $>$. Acesso em: 21 maio 2011 .

SANTOS, Boaventura de Souza. Pela mão de Alice: o social e o politico na pós-modernidade. 3. ed. São Paulo: Cortez, 1997.

SCHNORR, Giselle Moura. Pedagogia do Oprimido. In: SOUZA, Ana Inês et al. Paulo Freire: vida e obra. 2. ed. São Paulo: Expressão Popular, 2010. 